\title{
On Some Borrowed and Misunderstood Problems in Greek Catoptrics
} by

\author{
AleXander Jones
}

Optics was one of the first sciences to which ancient Greek mathematicians attempted to apply the apparatus of geometry. They were most successful in describing geometrically certain phenomena of perspective (as in Euclid's Optics and parts of Pappus's Collection, Book 6), less so in catoptrics, the study of mirrors. ${ }^{1}$ The problems typically encountered in the surviving writings on catoptrics fall into two classes: those dealing with the reflection of rays cast from a luminous source such as the sun upon mirrors of plane or curved surface, and those involving the projection of lines of sight from the eye by way of a mirror to an object. The most basic problem of the first class, to make a burning mirror, is solved correctly in Diocles's On Burning Mirrors (ca. 200 B.C.) with both spherical and parabolic mirrors; other problems were investigated by Diocles, by Anthemius (ca. A.D. 620) in his On Paradoxical Devices, and doubtless by other authors in the centuries between. ${ }^{2}$ In general these problems were amenable to geometrical treatment in antiquity because Hellenistic geometers were equipped to study the tangent lines to a wide range of curves (or the tangent planes to analogous surfaces) and the behaviour of straight lines in a given direction or through a given point and inflected at the curve or surface at equal angles to the tangent at the point of incidence.

Problems of the other class, in which it was required to make an arrangement of mirrors or a mirror with a special curvature, such that a

\footnotetext{
*Institute for the History and Philosophy of Science and Technology, Victoria College, University of Toronto, Toronto, Canada M5S 1K7.
}

Cemuurus 1987: vol. 30: pp. 1-17

1 Centourus XXX 
viewer would see a specified kind of image, could sometimes be less tractable, for two reasons. First, the problem of determining the point or points of reflection on a curved mirror for a given position of eye and object was solved only for special cases; thus Ptolemy, Optics Book 4, could only solve the problem for a circular mirror ("Alhazen's problem") for special positions of the eye and object. Secondly, the problems themselves were often not easily translated into mathematical terms: for example, "to make the viewer see himself with three eyes and two noses". As a consequence most of the extant treatises on mirrors (the exception is Ptolemy's Optics) contain either theoretical treatments of fairly easy assignments concerning reflected images, or empirical solutions of the more elaborate tasks (or a mixture of the two).

Another trait of these treatises, which I intend to elaborate upon here, is their dependence on one another and on common lost sources for problems and their solutions. The borrowings not only illuminate the question of originality and tradition in a branch of science where it is seldom possible to give the credit for innovations to specific people; they also illustrate a tendency of the adaptors to metamorphose their models, sometimes intentionally, but surprisingly often through misunderstanding. Because of such misunderstandings, these writings can be treacherous for modern readers who must try to recover the original line of thought.

I have chosen problems from four works: pseudo-Euclid's Catoptrics, pseudo-Ptolemy's De Speculis, Anthemius's On Burning Mirrors and other Mirrors, and Witelo's Perspectiva. The inclusion of Witelo in this list will be explained presently; the other books comprise practically the whole surviving corpus of ancient writings on the class of catoptrical problems that we are considering. One of the aims of the present paper is to demonstrate that the contents of all three are in part interdependent. Anthemius's work proyes to be largely a plagiarization of the treatise (apparently the Catoptrics of Heron) of which pseudo-Ptolemy is to some extent an abridgement. In turn, some theorems of pseudo-Ptolemy (or Heron) coincide with those of pseudo-Euclid, but a few, while deriving their inspiration from pseudo-Euclid - or his lost sources - in fact set out to show quite different things. The Catoptrics of pseudo-Euclid is itself admitted to be a heterogeneous compilation. What sort of original treatises, now lost, 
were the ultimate sources of this derivative tradition, is a question that will perhaps never be answered satisfactorily.

More detailed descriptions of the four works in question are given immediately below. In the remainder of this article, I will consider all the cases known to me in which related theorems or problems appear in more than one of our works, with a view to deducing the nature of their relationships. In passing I will also attempt to clarify some particular difficulties in the texts and their interpretation.

\section{Descriptions of the Works:}

The authenticity of the Catoptrics attributed to Euclid has been doubted since Heiberg showed how its style, terminology, and geometrical competence were not those of Euclid in his Optics and other authentic works. ${ }^{3}$ Moreover, Lejeune has analysed the Catoptrics into several levels of composition that would reflect the state of the science of mirrors in the early Hellenistic period (before Archimedes, perhaps the real Euclidian contribution), in the last centuries B.C. or the first century of our era, and thirdly in late antiquity. The most that we can say for the date of the Catoptrics in its present form is that it appears consistently in manuscripts (tenth-century and later) of a corpus of treatises useful for sub-Ptolemaic astronomy, which was probably established as we have it now in the early Byzantine period; a reference by Proclus in his commentary on Book 1 of the Elements (p. 69, Ziegler) to a Catoptrics by Euclid could conceivably be to another treatise, authentic or spurious. Theon of Alexandria, who produced editions of Euclid's Elements and Data in the late fourth century, is often suggested as the compilator of the Catoptrics, but the underlying assumption, that there were not many other pedagogues about Theon's time whose activity was comparable to his, is entirely unwarranted. I will refer to the edition of the Catoptrics by Heiberg in the Teubner edition of Euclid's works. ${ }^{\text {s }}$

The Liber de Speculis that goes under the name of Ptolemy survives only through the Latin translation that William of Moerbeke made of it in 1269 from a lost Greek exemplar. William's autograph of the translation is extant, now Ottob. lat. 1850. Ptolemy certainly did not write this De Speculis, the frivolous problems of which, not to speak 
of their executions, are on a far lower level than Ptolemy's great scientific writings, including the Optics. The modern rediscoverer of the work, Valentin Rose, proposed that it preserved Heron's Catoptrics, and Schmidt, who edited it in the Teubner Heron, considerably strengthened the argument. ${ }^{6}$ The strongest evidence is the citation, by Damianus Heliodorus of Larissa (author of a short book on optics in late antiquity), of a theorem found in De Speculis as being from Heron's Catoptrics; and there are several impressive verbal parallels between the introduction to De Speculis and passages in Heron's works. De Speculis is however surely not Heron's original composition, but at best an abridgement of it in which there may be extraneous material. The date of the book is uncertain; Heron himself lives about the second half of the first century of our era.' I refer to De Speculis following the chapter numeration of Schmidt's edition.

Anthemius of Tralles is well known for his architectural and thaumaturgical activities in Constantinople during the reign of Justinian (early sixth century), and for his On Paradoxical Devices, a work on mirrors that survives only incomplete in Greek. ${ }^{8}$ This opuscule and another, On Burning Mirrors and other Mirrors, were translated into Arabic however, and a slightly revised and quite corrupt recension of the two by the late ninth-century polymath 'Uțārid ibn Muhammad can be found in an Istanbul manuscript, Laleli $2759 .{ }^{\circ}$ We are here concerned only with the second of these writings. Since it is not now available for reference in print, I give a summary of its contents:

1-2. Construction of a spherical burning mirror, and (incorrect) determination of its focal distance.

3. Erection of two mirrors so that the viewer can see himself from front and back simultaneously.

4. Erection of a mirror so that the viewer sees a predetermined image.

5. Construction of a mirror to reverse right and left.

6. Construction of a mirror to show two heads on one body.

7. Construction of a mirror to show four eyes.

Our last work. Witelo's Perspectiva, was written in the 1270 's at the request of Witelo's friend William of Moerbeke. It is of course not directly a part of the history of Greek optics, but Witelo's extensive ap- 
plication of his Greek as well as Arabic sources, practically unparalleled in the mathematics of the Latin middle ages, is of considerable historical interest, especially since the Perspectiva continued to be influential for several centuries afterwards. The discussion of Witelo's adaptations in this article has a complementary purpose to the analysis of the ancient works. As was not the case for them, we seem to have all his sources, and so we can isolate exactly what he owed to each, and what was his original work. Witelo was able to consult Latin translations of pseudo-Euclid's Catoptrics and pseudo-Ptolemy (the latter in William's version, the former in a 12th-century south-Italian translation from Greek). Moreover, he possessed several propositions from Anthemius's On Burning Mirrors and other Mirrors translated from Arabic, because these had found their way into a compilation of Arabó-latin material on optics that went by the title tractatus Euclidis de speculis. " The Anthemian propositions 1-3 in this De Speculis apparently derive from the Arabic translation of On Burning Mirrors before 'Uțārid's revisions. I have used Risner's 1572 edition of Witelo. ${ }^{12}$

\section{Analysis of individual problems and theorems:}

Some theorems appear in nearly identical form in both pseudo-Euclid's Catoptrics and the more theoretical first part of pseudo-Ptolemy, but these call for little comment. Thus pseudo-Ptolemy's proof (Schmidt 7-8) that lines of sight reflected by plane or convex circular mirrors neither intersect nor are parallel corresponds to pseudo-Euclid proposition 4, and his proof (Schmidt 9-10) that lines of sight from an eye at the center of a convex circular mirror will be reflected back to the eye, whereas if the eye lies on the circle's circumference the lines of sight intersect after reflection, corresponds to pseudo-Euclid proposition 5. However, pseudo-Euclid works this kind of theorem out more thoroughly, considering (proposition 6) also the case of an eye situated between the center and circumference.

But another proposition of pseudo-Ptolemy (Schmidt 6) has more than coincidental verbal parallels with pseudo-Euclid, while asserting something quite different. The fourth axiom at the beginning of the Catoptrics asserts that "in plane mirrors, when the place is occupied on which the perpendicular from the seen thing falls, the seen thing is 


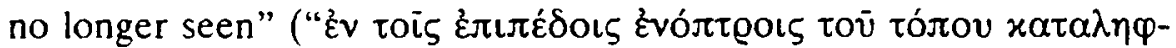

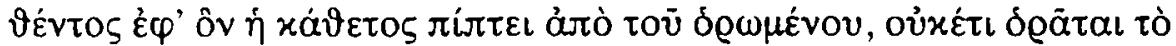
$\delta \varrho \omega \mu \varepsilon v o v ")$. Lejeune gives an interpretation of this obscure expression that is undoubtedly correct: ${ }^{13}$ if an opaque obstruction is put on the surface of the mirror where the perpendicular from the object falls on it, the viewer will not see the object reflected in the mirror. He also suggests how this absurd law could have been deduced by fallacious theoretical reasoning from the importance in ancient optics of the perpendicular dropped from the object in determining the position of the image.

Pseudo-Ptolemy uses words that, before translation, must have been nearly identical to pseudo-Euclid's: "In plane mirrors, there is some place such that when it is occupied, the image is no longer seen" ("in planis speculis est aliquis locus quo apprehenso non adhuc uidetur ydolum"). The difference is deliberate, for pseudo-Ptolemy sets out to prove that the place that has to be 'occupied' is, not the foot of the perpendicular from the object, but the point where a reflection can occur at equal angles to the mirror. The relationship between the two texts raises a historical question of some importance. Lejeune has maintained that the principal axioms of pseudo-Euclid, including the fourth axiom which we have discussed here, are late and decadent derivatives of the laws of reflection enunciated by Ptolemy, Optics Book $3,3 .{ }^{14}$ But is it plausible that an author even in late antiquity could have taken pseudo-Ptolemy's enunciation, which is not only correct but proved to be so, and perverted it into the baldly asserted nonsense that we find in pseudo-Euclid? I suspect rather that the compilator of pseudo-Ptolemy, or his source (Heron?), had seen pseudo-Euclid's axiom, and retained its idiosyncratic phraseology while applying it to a sounder theory.

One more parallel between the two texts supports the hypothesis that the contents of pseudo-Ptolemy are more or less derivative from pseudo-Euclid, and not the other way around. Pseudo-Ptolemy has a proposition (Schmidt 17) that "it is possible to see the same image in many mirrors set in some sequence" ("in pluribus speculis positis in ordine aliquo possibile est idem ydolum uideri"). The construction and proof are as follows (see figure 1): 


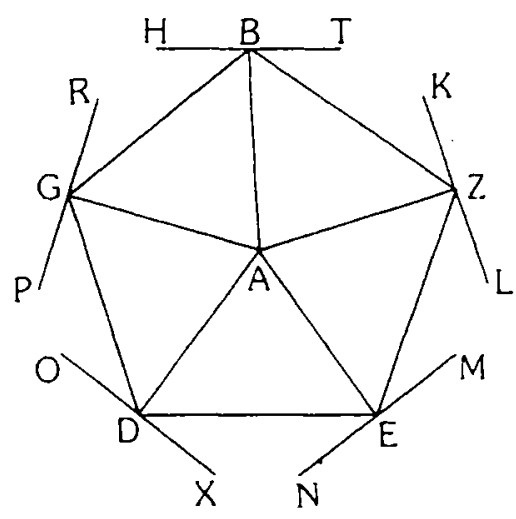

Figure 1.

Let $A$ be what we want to see in many mirrors, and let $B, G, D, E, Z$ be any number of equilateral and equiangular mirrors, and let $A$ be their middle, the center of the circle that circumscribes them. And let $A B, A G, A D, A E, A Z$ be joined, and let $H T, K L, M N$, $X O, P R$ be drawn at right angles to plane $B G D E Z$. I say that lines of sight falling on the mirrors will be reflected to $A$. For as they fall they will make right angles with the mirrors. Hence they will have their reflections in themselves. Thus they will be reflected to A.

This proposition is as straightforward as it is inconsequential: no one probably would suspect from examination of it by itself that pseudoPtolemy or his source had adapted it from a quite different theorem. Yet that is nevertheless the case. Pseudo-Euclid's proposition 14 is as follows (figure 2).

It is also possible to see the same thing through as many mirrors as one assigns. One must, in accordance with the number of mirrors, construct an equilateral and equiangular polygon having two more sides than the mirrors.

For let $A$ be what has to be seen, $B$ the eye, and let $A B$ be joined, and on $A B$ let there be erected an equilateral and equiangular polygon having two sides more than the mirrors, and let it be polygon $A B D$, and let the center $T$ of the circle circumscribing the polygon be taken, and let $T G, T E, T D, T B, T A$ be joined from it to the angles, and let plane mirrors be adjoined at right angles to the lines that were joined. Then since angle $z+l$ equals angle $n+k$ (because both are right), and out of them angle $n$ equals angle $l$, the remaining angle $z$ therefore equals angle $k$. Hence the reflection of line of sight $B G$ will be to $D$, since the reflections occur at equal angles. Similarly the angles with respect to the mirrors at points $D$ and $E$ will be shown to be equal. Thus the line of sight from the eye, $B$, reflected and falling upon all the mirrors, will come to $A$. 


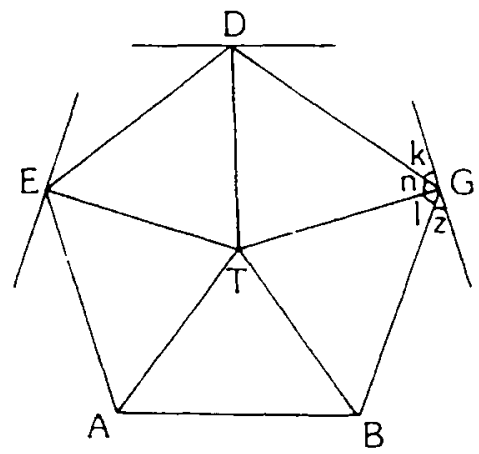

Figure 2.

The ancestry of pseudo-Ptolemy's theorem in pseudo-Euclid's is evident from the survival in the former of elements in the latter that were either arbitrary or necessary only for pseudo-Euclid's purpose. For example, the requirement to construct an equilateral and equiangular polygon is valid for pseudo-Euclid, but pseudo-Ptolemy could have chosen points at random and erected mirrors through them at right angles to the lines from the eye (the transference of the attributes of equiangularity to the mirrors themselves is a secondary error). The pentagonal figure in both, to illustrate propositions admitting an arbitrary number of mirrors, is a coincidence that is emphasized by the fact that neither text uses the minimum possible number of mirrors required to establish its point. The reason for the metamorphosis is not obvious; perhaps the author of pseudo-Ptolemy's theorem had at his disposal only the enunciation and figure for the earlier theorem, and reconstructed from sheer wits a banal but possible interpretation of the enunciation.

We shall turn now from the relationship between pseudo-Euclid and pseudo-Ptolemy to the relationships connecting pseudo-Ptolemy with Anthemius and Witelo. It will be apparent that Anthemius is naively dependent on pseudo-Ptolemy (or rather his source), whereas Witelo makes serious, if sometimes misguided, efforts to reconcile his several corrupt sources.

The last of pseudo-Ptolemy's problems (Schmidt 18) is "to put a mirror in a given place, so that everyone who approaches it will see neither himself nor someone else, but only whatever picture someone 


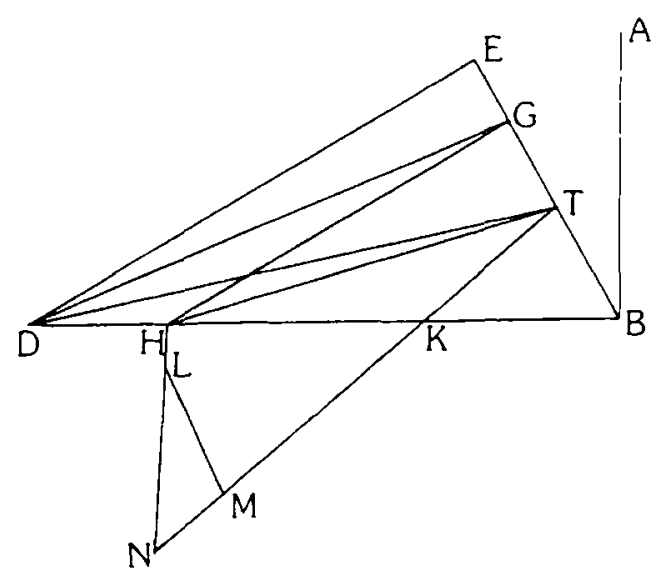

Figure 3.

has chosen in advance". The construction proceeds by analysis and synthesis (in the Greek sense), although the separation between the two stages is less clearly defined than in purely geometrical writings (see figure 3):

[Analysis] Let $A B$ be the wall on which the mirror is to be put, and let the mirror be inclined at some angle to it. It will be suitably proportioned if the angle is one third of a right angle. And let $B G$ be the mirror's surface, and let $B D$ be imagined at right angles to $A B$ from $B$, and let the point of sight so lie in $B D$ that a perpendicular produced from it to the mirror $B G$ will fall outside it. Let it be $D E$. And let $D G$ be joined from $D$ to the edge of the mirror, and let angle $H G D$ be made equal to angle $E D G$. Then if some ray falls from sight $D$ upon the edge $G$ of the mirror, it will be reflected to $H$. So let $H N$ be drawn from $H$ at right angles to $D B$. And let another ray $D T$ be incident, and let $H T$ be joined. Then angle $B T H$ is greater than angle ETD. So let angle $B T K$ be made equal to angle $G T D$. Hence $T K$ will cut $H N$. Likewise all rays that fall upon the mirror will be reflected and cut $H N$. Then let the plane $L M$ be drawn parallel to mirror $G B$, and let it lie between $H$ and $N$, cut by the reflected ray. Hence it is obvious that the eye will see nothing other than whatever lies between $H$ and $N$. Let us therefore put whatever picture we want in plane $L M$, and no one who approaches will appear, but only the picture mentioned. Hence $H N$ should be a sort of screen, so that the mentioned picture will lie in a plane parallel to the mirror.

[Synthesis] Line $A B$ should therefore be produced in some plane and angle $A B G$ should be made one third of a right angle, and $B G$ should be made equal to the height of the mirror, and it should be produced to $E$; and $B D$ should be produced at right angles to $A B$ and some point $E$ chosen so that $E D$ produced at right angles will fall outside $M[!]$. 
Let it be chosen, and let it be $E$, and let $E D$ be at right angles to $E B$, and let $D G$ be joined. And let angle $H G D$ be made equal to angle $E D G$. And let $H N$ be drawn at right angles to $D B$. Then with the mirror inclined, as has been said above, one should stand back from the wall by a distance equal to $B H$, and an upright obstacle should stand there, a coffer open at the top and as tall as a man, and plane $L M$ should be inserned parallel to the mirror, and the mentioned picture should be put in it. The sight should stand at $D$, with something there to block him from moving closer. For in this way rays that fall upon the mirror will not land outside the screen, but within it, where the picture is. [Suggestions follow for the disposition and illumination of the display.]

Pseudo-Ptolemy's construction has several surprising details. In the analysis, angle $D G D$ is made equal to angle $E D G$, so that $G H$ is parallel to $D E$ and hence perpendicular to the mirror; yet the text asserts that ray $D G$ will be reflected along $G H$. Later, point $L$ on line $H N$ is used but not defined. Maybe in the lost original version of the proposition, after constructing $G H$, one made angle $L G H$ equal to angle $H G D$ too, so that $G L$ would be the correct reflection of $D G$. Again, the next step in the construction would be more intelligible if $T$ were the bottom of the mirror, so that $L M$ or $L N$ would occupy the whole range of reflection of the mirror, as our author asserts. On the other hand, the stipulation that $L M$ be parallel to the mirror, instead of being $60^{\circ}$ from vertical so that the image would be vertical, is a mistake of small importance and could have been already in the prototype.

Parts of the synthesis, as we have it, are nonsensical. We are told to choose $E$ on $B G$ produced, "so that $E D$ [my conjecture; the text has $E B$ ] produced at right angles [to $B G$ ] will fall outside $M$ ". Point $M$ is out of the question, since it is not determined until later in the synthesis, and in any case if we construct in this way, any point $E$ beyond $G$ will suffice. Practically it would make more sense to begin by finding a point $D$ from which the perpendicular to plane $B G$ is beyond the mirror (that is, if one stands at $D$, one cannot see one's own reflection). Confusions of this kind make it difficult to accept pseudo-Ptolemy as merely an abridgement of Heron's Catoptrics: clearly some sort of unintelligent revision has contaminated the arguments.

Anthemius (section 4 = pseudo-Euclid De Speculis 1 ) has a version of this problem that seems to depend on pseudo-Ptolemy. He follows pseudo-Ptolemy's analysis fairly closely as far as the construction of vertical $H N$ (for convenience I disregard the discrepancies between Anthemius's and pseudo-Ptolemy's lettering schemes, which are not 


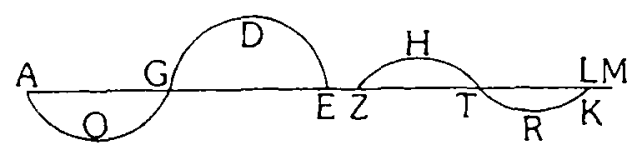

$N$

Figure 4 .

important). Then he makes $L M$ parallel to the mirror, with $H L$ (an error for $L M$ ?) equal to $G B$; and with the picture placed along $L M$, the construction is finished. Anthemius has nothing corresponding to pseudo-Ptolemy's bungled synthesis.

Witelo's version of the same problem (V 56) is indebted to both his predecessors, for while he uses the same lettering scheme as Anthemius (through the medium of pseudo-Euclid De Speculis), the details of his construction adhere more closely to pseudo-Ptolemy, although with improvements. Specifically Witelo constructs line $G L$ as the correct reflection of $D G$, and $B M$ as the correct reflection of $D B$. The long demonstration of the construction's validity owes nothing to the ancient authors.

Another of Witelo's problems unexpectedly draws all three of our other authorities into play. First, there is a proposition of pseudo-Euclid, Catoptrics 29, that "it is possible for a mirror to be constructed so that numerous faces appear in the same [mirror], some bigger, some smaller, some nearer, some farther, some with right as right and left as left, some with left as right and right as left" (figure 4):

For let there be plane $A M$. Then on this would be convex mirrors such as $A O G, T R K$, convex ones such as $G D E, Z H T$, plane ones such as $E Z, L M$. So with the face placed where $N$ is, the images appear equal and equally distant in the plane mirrors, smaller and nearer in the convex mirrors, and in every manner in the concave mirrors, just as has been shown.

Secondly, there is pseudo-Ptolemy's proposition (Schmidt 11) "to construct a dextral mirror" (figure 5):

Let circle $A B G$ be described in the size in which we want to fashion the mirror. And let there be inscribed in it the side $A B$ of a pentagon and $B G$ that of a hexagon, and let tem- 


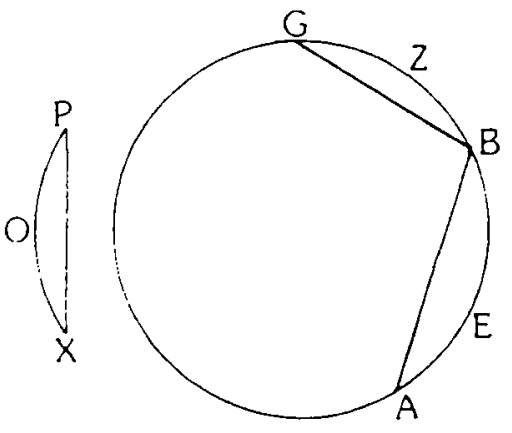

Figure 5.

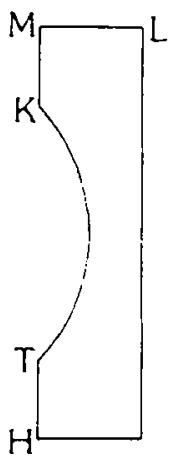

plates be cut according to arcs $A E B$ and $B Z G$ which are cut off from the circle by lines $A B$ and $B G$ : let the template for the height be made concave according to arc $A E B$, as $H T K L M$ : and let the template for the breadth be convex, according to arc $B Z G$, as $X O P$. And let a rectangular mirror on a base be prepared, having height equal to line $A B$, and breadth equal to $B G$, and let its vertical surface be convex, worked against the concave surface of template $A E B$, and its horizontal surface concave, worked against the convex arc of template $B Z G$.

Right will appear as right, and left likewise as left. And when the sight is about two cubits away, the image will appear in proper proportion and realistic. But when the sight is farther away, the image of the person who is seen will seem to stretch backwards; while as the sight approaches closer towards the convex surface of the aniror, the image of the person who is seen monstrous, the more so the closer it gets. And the mirrored person will be reversed, and contrariwise as the sight still approaches the image will appear farther away, and the face becomes like a form of horse. And as the mirror is progressively titled. the image will appear tilted. One should therefore prepare a stand with a universal joint for it, on which the mirror is kept, so that the image that is seen will sometimes have its head up, sometimes down and feet up. If the mirror is made with two faces, that is on the back and front, then right will appear as right, but from the rear it will exhibit people head-over-heels like antipodites.

This construction has, I believe, not been explained correctly before, although pseudo-Ptolemy's instructions are fairly clear ${ }^{15}$ The surface of the mirror is to be shaped by filing so that its vertical sections are all convex circular segments, and its horizontal sections are all concave circular segments with uniform radius. The lateral concavity of this saddle surface reverses the right and left of the image, while the bulge in the other direction compresses the figure vertically to roughly equal the horizontal compression, so that the image looks fairly well 
proportioned from a reasonable distance ("two cubits" is meaningless when the dimensions of the mirror are not given). The several phenomena that pseudo-Ptolemy describes for different positions of mirror and viewer seem to be drawn from experimentation, although his meaning in some instances is unclear (for example the sense of "tilted"). The choice of circular segments cut off by sides of a pentagon and hexagon is arbitrary, and presumably intended to give a slightly oblong mirror matching the proportions of a face.

Anthemius adapts pseudo-Ptolemy's construction in a way that reveals how little experimentation contributed to his writing (section 5 $=D e$ Speculis 3): he forgets to make the vertical curvature convex, so that the mirror will reverse top and bottom as well as right and left. Nevertheless he repeats pseudo-Ptolemy's assertion that rotating the mirror will cause the effect to change from lateral to vertical inversion. The other phenomena are not mentioned.

Witelo, IX 35, draws mostly on pseudo-Ptolemy, although his clear understanding of the use of the templates may be derived from the more explicit description of the filing in De Speculis (William of Moerbeke had difficulties with the Greek terminology in translating this passage of pseudo-Ptolemy, leaving lacunas in the text with tentative glosses in the margin). However, Witelo too was confused by the instructions for the double filing. He changes the proportions of the mirror-to-be so that while the breadth still equals $B G$, the height equals not $A B$ but $A B+B G$. Then, instead of filing against the templates in perpendicular directions on the same surface, he files the bottom length of the mirror (equal to $A B$ ) vertically against the concave template, and the remaining top length (equal to $B G$ ) horizontally against the convex template (so one must interpret the obscure phrase "et eius latitudo sit in parte longitudinis residuae concauitatis portionis GZB"). This produces simply two cylindrical mirrors, one on top of the other, and at right angles to each other with respect to their curvature. Witelo repeats pseudo-Ptolemy's catalogue of phenomena, which however are not truly effected by his own double mirror; and he adds the disingenuous remark that "experience will teach the varieties of images more than description". But the motive for this misinterpretation of pseudo-Ptolemy is made evident by what follows: Witelo goes on without interruption from his two-part mirror to a more complicated compounding of convex, concave, and 


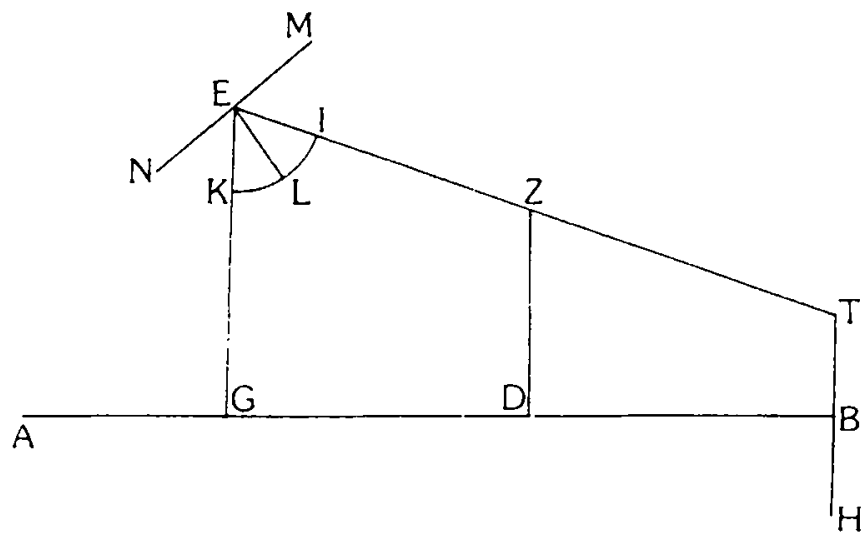

Figure 6 .

plane mirrors which is none other than pseudo-Euclid's arrangement quoted above.

Anthemius has three more problems of a similar character to the two mentioned above; and while they are not paralleled in the earlier works, their pedigree can perhaps be inferred. The first (section $3=$ De Speculis 2) is "how two mirrors are to be erected so that the person is seen in one of them from front and back". Anthemius's solution (figure 6) is as follows:

You draw a line of length four cubits labelled $A B$, and cut off from it a section equal to a quarer of the width of the mirror, namely $A G$, and you bisect line $G B$ at point $D$. You draw from point $D$ a line at right angles, equal to the mirror's width, namely line $D Z$; and you draw from point $B$ a line at right angles, equal to half the mirror's width, namely line $B T$. You join point $T$ to point $Z$, and extend it in a straight line without limit. You draw from point $G$ a line at right angles to meet $T Z$ at point $E$, and, making point $E$ center, you describe a section of a circle with whatever radius you want, namely arc $I K$. You bisect it at point $L$ and join point $L$ to point $E$. You draw on the two sides of $L E$ from point $E$ two lines at right angles [to $L E$ ], one of them sticking to the other in a straight line, so that both their lengths on the two sides equal the mirror's width, [and let them be] lines $E N, E M$. You draw from point $B$ a line sticking in a straight line to line $B T$ and equal to it, namely line $B H$. If we do this exactly as we have described, and erect one of the two mirrors along the line $M N$ so that line $M N$ bisects it [laterally], and erect the other mirror along line $T H$ so that line $T H$ bisects it [laterally], and the position of the eye is $D$, then what we said will occur, namely that the figure will be seen in a mirror $M N$ from front and back. The size of the two mirrors is equal, and they are square.

There is no evidence in this exposition that it was verified theoretically 
or empirically. In fact some details of the construction appear to be mistaken, for example the exceedingly small size of the room (four cubits, about two meters), while others, including the size of the mirrors, should have been given. These oversights suggest that Anthemius again did not invent the problem, but borrowed it from elsewhere. Now, pseudo-Ptolemy's preface contains a passage (Schmidt 1) in which he lists some of the wonderful things that mirrors can do, and these include not only problems that are solved in our text of pseudo-Ptolemy, but also a few others, among them "to see [oneself?] coming from behind" ("uidere posterius apparentes"). This preface is one of the parts of pseudo-Ptolemy that show evidence through verbal parallels of Heronian authorship, and so the list is likely an indication of the partial contents of the original Catoptrics of Heron, not all of which were usurped by pseudo-Ptolemy's compilator. A more complete text of Heron's book was presumably still extant in the sixth century in Constantinople, where Anthemius plundered it.

The Latin translation of Anthemius's front-and-back mirror in $D e$ Speculis is twice flawed. First, it makes $D Z$, as well as $B T$, equal to only half the mirror's width. Then it omits the instruction to put the second mirror along line $T H$. Moreover, instead of showing the viewer "from front and back", the enunciation has the mirrors display him "coming and going" ("uenientem et recedentem"). Witelo (IX 64), trying to recover sense in this mangled proposition, puts both mirrors along $M N$, but capable of swinging around a hinge at $E$, so that by some sort of apparatus the viewer's image can be made to wave backwards and forwards.

Finally, the two last problems of Anthemius (6 and 7), which were not included in the Latin De Speculis, are to make mirrors showing the viewer with two heads on one body, and with four (or eight) eyes. These are done by dividing a rectangle into regions filed plane, or concave against templates that again are cut off from a circular board by the sides of regular polygons. Some details of the constructions are obscure, but the fault may belong to the Arabic translation, not Anthemius. Again, it is worth pointing out that pseudo-Ptolemy's preface mentions mirrors showing the viewer "having three eyes and two noses and a likeness of grief with the parts of the face scattered" ("habentesque tres oculos et duos nasos et luctus instar dispersis partibus faciei"). 
To summarize, the foregoing comparison of passages from four ancient and medieval books on catoptrics invites inferences about each. Pseudo-Euclid's Catoptrics, or a text closely related to it, was a source of pseudo-Ptolemy, and so the manner and date of its composition as proposed by Lejeune may need further investigation. Pseudo-Ptolemy itself clearly should not be identified with Heron without qualification: not only were there probably many more problems in Heron's work, but some of pseudo-Ptolemy's constructions (e.g. 17 and 18) contain essential mistakes that one would hesitate to ascribe to Heron. Anthemius's responsibility for On Burning Mirrors and other Mirrors is not in question, but one may wonder whether any of its contents are his own invention, and whether his other work On Paradoxical Devices too is a magpie's nest. Lastly, Witelo's versions of the old propositions reveal not only his practice of using the widest selection of materials available to him, but also the freedom with which he employed them, sometimes restoring corrupted details, sometimes disastrously misunderstanding the basic purpose of the construction, but usually aiming for a coherent and correct result.

\section{Acknowledgement}

This paper was written under fellowship from Dumbarton Oaks and the Institute for the History and Philosophy of Science and Technology (University of Toronto). I have to thank Gerald Toomer and Marshall Clagett for photographs of manuscripts.

\section{ABBREVIATION}

RCG. A. Lejeune, Recherches sur la catoptrique grecque, Brussels 1957 (Acad R. de Belgique. Mémoire 52.2).

\section{NOTES}

1. For the development of Greek optics, A. Lejeune's masterly books have not been surpassed: Euclide et Ptolémée: Deux stades de l'optique géométrique grecque, Louvain 1948; and $R C G$. 
2. Diocles, On Burning Mirrors, ed. G. J. Toomer, Berlin etc. 1976. Anthemius, in Mathemaitci Graeci Minores, ed. J. L. Heiberg, Copenhagen 1927 (Det Kgl. Danske Videnskabernes Selskab. Histor. filol. Meddelelser 13.3), 77-87.

3. J. L. Heiberg, Litterargeschichtliche Studien über Euklid, Leipzig 1882, pp. 148-53.

4. RCG 112-36.

5. Euclid, Opera vol. 7, Leipzig 1895, pp. 286-343.

6. V. Rose, Anecdoto Graeca et Graecolatina vol. 2, Berlin 1870, pp. 290-96; Heron, Opera vol. 2.1, Leipzig: 1900, pp. 301-15 (Schmidt's preface), 316-65 (edition), 406-15 (indispensible addenda). Quotations and transiations of pseudo-Ptolemy in this article are from a new edition that $I$ am preparing.

7. O. Neugebauer, "Über eine Methode zur Distanzbestimmung Alexandria-Rom bei Heron", Det Kgl. Danske Videnskabernes Selskab, Histor.-filol. Meddelelser 26.2 (1938).

8. G. L. Huxley, Anthemius of Tralles, A Study in Later Greek Geometry, Cambridge, Mass. 1959 , usefully collects the biographical data.

9. M. Krause, "Stambuler Handschriften islamischer Mathematiker", Quellen und Studien zur Geschichte der Mathematik, Astronomie und Physik B 3 (1936) 437-532, pp. 465-66; Toomer, Diocles (note 2), 20.

10. I am preparing an edition of the Arabic Anthemius. In another article I will discuss the sections on burning mirrors.

11. Edited in A. A. Björnbo \& S. Vogl, "Alkindi, Tideus and pseudo-Euklid: Drei optische Werke", Abh. zur Geschichte der math. Wiss. 26.3 (1912) 97-119.

12. F. Risner, Opticae Thesaurus. Alhazeni Arabis libri septem ... Vitellionis Thuringopoloni libri X ..., Basle 1572. Reprinted New York 1972.

13. $R C G 62-66$.

14. $R C G$ 66-67.

15. The interpretations by Vogl (in the edition of De Speculis, note 11 above, p. 109) and Schmidt (pp. 337-43 and 406-408) are incorrect. 